\title{
Aproximación fenomenológica a la conversión súbita ${ }^{1}$
}

\author{
José María CONTRERAs EsPunY \\ Hankuk University of Foreign Studies (Seúl) \\ josemcontrerasespuny@gmail.com
}

\section{RESUMEN}

Partiendo del estudio filológico y filosófico de textos autógrafos clásicos (Agustín de Hipona) y del siglo XX (Paul Claudel, André Frossard, Max Jacob, Manuel García Morente), se pretende la fijación de un esquema fenomenológico que se repite en los casos de conversión súbita en el ámbito católico, así como las imágenes arquetípicas que aparecen. Asimismo, se busca la catalogación de la conversión súbita dentro del estudio contemporáneo de la fenomenología de las religiones.

Palabras clave: fenomenología, literatura, conversión súbita, catolicismo.

\section{Phenomenological approach to the sudden conversion}

\begin{abstract}
By drawing on the philosophical and philological study of classics autographed texts (Augustine of Hippo) and from the XX century (Paul Claudel, André Frossard, Max Jacob, Manuel García Morente), we pretend to determine a phenomenological scheme that it repeats in the cases of sudden conversion in the catholic field, as well as the archetypal images that appears. Therefore, we look for the sudden conversion cataloguing inside the contemporary studies of religion phenomenology.
\end{abstract}

Keywords: phenomenology, literature, sudden conversion, Catholicism.

SUMARIO: 1. Introducción. 2. Definiciones y perspectivas. 2.1. Concepto de conversión religiosa. 2.2. Enfoque disciplinar. Perspectiva fenomenológica. 2.3. La experiencia como forma legítima de conocimiento. 2.4. Particularidades de la experiencia. Fenómeno saturado. 2.5. El recuerdo como activación de la experiencia. 3. Rasgos fenomenológicos comunes. 3.1. La intuición como realidad de la experiencia. 3.2. Gracia: la iniciativa de Dios, sujeto activo. 3.3. Contenido de la teofanía desde el sujeto paciente. 3.4. El Hombre nuevo como imagen predilecta. 3.5. Consecuencias vitales de la teofanía. 4. Conclusiones. 5. Bibliografía.

FECHA DE RECEPCIÓN: 11 DE 03 DE 2015 FECHA DE ACEPTACIÓN: 31 DE 08 DE 2015

${ }^{1}$ This work was supported by Hankuk University of Foreign Studies Research Fund. 


\section{INTRODUCCIÓN}

En el ámbito cristiano se entiende por conversión el paso de la increencia a la fidelidad mediante el encuentro con Cristo. No obstante, son muchas las posibilidades que la historia nos ha mostrado de este proceso -intelectual, experiencial, comunitaria, etcétera-. Aquí nos centraremos en los casos de conversión súbita ${ }^{2}$ : cambios instantáneos producidos por una experiencia concreta, normalmente de índole sobrenatural. Algunos la han calificado como «paulina» dada la semejanza con el caso de Pablo de Tarso, relatada por Lucas en los Hechos de los apóstoles ${ }^{3}$.

Lo veremos en adelante: el cambio es puntual, del tipo «antes no y ahora sí», abrupto y, por lo general, basado en una experiencia efímera, aunque con consecuencias vitales definitivas. André Frossard, periodista y académico francés, a la hora de relatar su caso, se refiere a su texto autógrafo como «el atestado de un accidente» ${ }^{4}$. O en la misma página cuando afirma:

[...] ce livre ne raconte pas comment je suis venu au catholicisme, mais comment je n'y allais pas lorsque je me suis retrouvé chez lui ${ }^{5}$.

Es decir, nos interesan las conversiones, por así decirlo, sorpresivas e insospechadas, donde la fuerza renovadora irrumpe en la vida del sujeto transformándola por completo. Así, no podemos entenderlo como un proceso gradual o un itinerario espiritual, sino como un impacto, un choque con una entidad de tal magnitud, que el hombre queda indefectiblemente transformado. Desde luego cabría matizar lo abrupto de la conversión a la luz de acercamientos y tantas otras rugosidades que cualquier curso vital acumula, pero, en puridad, los testimonios de conversión súbita se basan en un acontecimiento concreto, puntual, sin prehistoria y definitivo, por lo que, con las reservas que aconseja la rigurosidad, no dudamos en hablar de conversiones súbitas y en oponerlas a otros procesos más intelectuales y paulatinos.

Además, como señala Jean-Louis Chrétien en Lo inolvidable y lo inesperado ${ }^{6}$, «sólo lo repentino puede hacer época» ${ }^{7}$, al irrumpir, sin partir de ninguna prehistoria, como inicio absoluto e inaugurando un nuevo tiempo en su novedad. Lo súbito, en este sentido, no sólo diferirá de lo gradual en cuanto a espectacularidad, sino que acarreará una serie de consecuencias fenomenológicas y vitales también desemejantes y propias de un proceso de estas características.

\footnotetext{
2 A propósito, William James recuerda las dos maneras en que, según la medicina antigua, podía curarse una enfermedad: Lysis - gradual-y Crisis -súbita-. En nuestro caso, tanto por el carácter súbito como por el curativo, estaríamos hablando de Crisis. Cfr. James 2002, 255.

${ }^{3}$ Hch. 9, 1-29; 22, 3-21; 26, 9-20.

${ }^{4}$ Frossard 1969, 8. Por su parte, Max Jacob habla de «explosión que de un golpe quemó mi pasado, en septiembre de 1909, e hizo nacer en mí un nuevo hombre.» Jacob 1965, 1475.

${ }^{5}$ Frossard 1969, 8. «[...] este libro no cuenta cómo he llegado al catolicismo, sino cómo no iba a él cuando en él me encontré».

${ }^{6}$ Cfr. Chrétien 2002, 119.

7 Chrétien 2002, 133.
} 
Nuestra intención, por ende, será bosquejar un armazón fenomenológico que, con muy pocas variantes -variantes que traslucirán la personalidad y finalidad de cada protagonista-, se repetirá en cada uno de los procesos que hemos dado en llamar «conversiones súbitas». Para la elaboración de esta estructura, hemos partido fontalmente de dos puntos:

a) Las conversiones cristianas clásicas, a saber, el caso de Pablo de Tarso según la fuente lucana, y el caso de san Agustín de Hipona según su escrito autobiográfico Las confesiones ${ }^{8}$.

b) Conversiones producidas o escritas en la primera mitad del siglo XX y contadas por sus propios protagonistas -de comprobada trayectoria intelectual-. Para este punto hemos seleccionado a los franceses Paul Claudel ${ }^{9}$, Max Ja$\operatorname{cob}^{10}$ y André Frossard ${ }^{11}$, y al filósofo español Manuel García Morente ${ }^{12}$.

Partimos del germen del fenómeno en los albores de la cristiandad para dar un salto prácticamente hasta nuestros días. Así, por un parte atestiguamos la vigencia del encuentro con la divinidad y, por otra, podemos entresacar lo común sin la sospecha historicista de la contemporaneidad. No habrá aquí un comentario filológico de los testimonios, sino que destacaremos y desmenuzaremos las múltiples simetrías entre los distintos procesos. Simetrías que pueden considerarse como un estrecho parentesco fenomenológico que parece indicar un mismo origen para todas estas experiencias marcadas por el prodigio.

\section{DEFINICIONES Y PERSPECTIVA}

\subsection{CONCEPTO DE CONVERSIÓN RELIGIOSA}

Según señala José Oroz en su estudio San Agustín. Cultura clásica y cristianis$m o^{13}$, el término castellano conversión proviene del latín conuersio que, a su vez, solía ser la traducción general del griego epistrophé. La conversión platónica, germen posible de la concepción cristiana, consistía en un proceso necesario para aquellos que se habían distanciado de su tendencia natural al bien moral. En un primer momento, esa lejanía empieza por ser diastrophé o auersio para luego derivar, si persiste y se recrudece, en katastrophé o peruersio. No obstante, siempre queda en el sujeto la capacidad de retornar al bien y alejarse de las fantasmagorías, en eso consiste la epistrophé o conuersio. Para el platonismo, ilustrado en el mito de la caverna, este retorno ha de obrarse gracias a una paideia de la interioridad, mientras que en la cosmogonía cristiana, esto no puede obrarlo el hombre por sí mismo, sino que precisa

\footnotetext{
${ }^{8}$ Cfr. Agustín de Hipona 2003.

${ }^{9}$ Cfr. Claudel 1965.

10 Cfr. Jacob 1965.

11 Cfr. Frossard 1969.

12 Cfr. García Morente 2002.

${ }^{13}$ Cfr. Oroz 1988, 205ss.
} 
de una gracia otorgada por Dios. El cristiano puede esforzarse para mejor recibir la llamada de Dios, pero la conuersio siempre corresponderá a la divinidad; de ahí que, en el lenguaje bíblico, se entienda la epistrophé como «una transformación total de la existencia bajo la acción del Espíritu santo» ${ }^{14}$. Si hubiera regreso, en el caso cristiano estaríamos hablando de un regreso pre-adánico, anterior al pecado. En este sentido, en las Sagradas Escrituras también encontramos el término metanóein, que hará referencia, más bien, al arrepentimiento del pecado; hecho íntimamente ligado con la conversión cristiana como veremos.

Así visto, todo hombre parte de una desfragmentación y una trágica confrontación de tendencias. Por una parte, en tanto que criatura de Dios, está ideado para la santidad, entendida como existencia en armonía con la voluntad divina. Por otra, en tanto que mordido apriorísticamente por el pecado original, halla en sí una inclinación a no corresponder ese plan divino. La conversión, por ende, no será ni natural ni lo contrario, ya que ambas tendencias o potencialidades se encuentran presentes en el individuo desde su nacimiento, y he ahí parte de la divergencia de la conversión cristiana respecto a la platónica.

Se ha visto claramente que la conversión en las religiones proféticas se emparenta estrechamente con los ritos de iniciación en las religiones del mundo antiguo. Es algo, por tanto, prototípico del itinerario religioso del sujeto, sea cual sea su tradición religiosa. La iniciación será el paso del mundo profano al mundo sagrado, donde la divinidad reorienta la vida haciendo de la existencia algo sacro. Es el descubrimiento de la divinidad y el deseo de vivir según ésta; lo que, en ámbito cristiano, se relaciona con el ejercicio de la fe. Dice Mircea Eliade al respecto:

Filosóficamente hablando, la iniciación equivale a una mutación ontológica del régimen existencial. Al final de las pruebas, goza el neófito de una vida totalmente diferente de la anterior a la iniciación: se ha convertido en otro ${ }^{15}$.

Así, la relación con la divinidad inaugurada transforma la existencia del iniciado, de tal forma que se habla incluso de un Hombre nuevo producido por un Nacimiento nuevo. Recordemos el pasaje de Jn. 3 donde Nicodemo interroga a Jesús a propósito del segundo nacimiento. Cristo le contesta:

En verdad, en verdad te digo: el que no nazca de agua y de Espíritu no puede entrar en el Reino de Dios. Lo nacido de la carne, es carne; lo nacido de Espíritu, es espíritu ${ }^{16}$.

La dicotomía evangélica carne vs. espíritu refleja la existencia-sin-Dios frente a la existencia-con-Dios. La conversión, como iniciación, marca este cambio que ha

\footnotetext{
14 Oroz 1988, 219.

${ }^{15}$ Eliade 1975, 10.

16 Jn. 3, 5-6.
} 
de obrar el creyente, por intercesión divina, para ser introducido en «la asamblea de los fieles», viviendo según el designio divino en adelante. En definitiva, se trata de la elección de una de las potencialidades que veíamos más arriba. Es, de cualquier forma, una elección impura en tanto que no se toma de una vez por todas, al menos no en esta vida. Pese a que una persona haya sufrido un proceso de conversión y optado por la vía divina, esto no le libra de futuros envites de la tendencia profana. Ambas inclinaciones pugnarán hasta el último momento, contagiado el discernimiento y la acción de la impureza del mundo en el que habita, mundo que no pertenece enteramente al Altísimo.

\subsection{ENFOQUE DISCIPLINAR. PERSPECTIVA FENOMENOLÓGICA}

Como anunciábamos, nuestra pretensión es el enfoque fenomenológico sobre los testimonios, siempre autógrafos -salvo en el caso de Pablo-. Pudiera verse como una tercera distancia: 1) lo que realmente pasó, 2) lo que el protagonista cree que pasó, $3)$ lo que narrador escribe que pasó. Considerar el punto 3 como punto 2 es inevitable, ya que, debido a la ausencia de testimonios contrarios, dado lo unipersonal de la experiencia, no hay posibilidad de contraste ni duda razonable para poner en tela de juicio el testimonio del narrador y único protagonista. Respecto al punto 1, nos auxilia Edmund Husserl en lo que se considera el acta fundacional de la fenomenología, porque la legitimación no proviene de lo que «es», sino de lo que el sujeto «percibió que era»:

Toda percepción inmanente garantiza necesariamente la existencia de su objeto. Cuando la reflexión se dirige a mi vivencia y la aprehende, aprehendo algo que es ello mismo un absoluto y cuyo estar ahí no es, por principio, negable, es decir, la evidencia intelectual de que no esté ahí es, por principio, imposible: sería un contrasentido tener por posible que una vivencia así dada, en verdad no existiese $^{17}$.

Así pues, consideraremos la indubitabilidad de la percepción inmanente del momento ontológico, adoptando un enfoque descriptivo y comparativo sin salir del marco de su testimonio. Nos alejamos, por tanto, de lo que Jean-Luc Marion ${ }^{18}$ califica como fenomenicidad alienada en Kant ${ }^{19}$, donde cualquier fenómeno ha de responder al principio de razón suficiente, así como al principio de posibilidad. Desde la perspectiva kantiana, cualquier fenómeno ha de plegarse a las condiciones de la experiencia general y a los parámetros del conocimiento, lo que condiciona el «darse» o el «aparecer» del fenómeno. En contra de este encorsetamiento, Marion

\footnotetext{
${ }^{17}$ Husserl 1993, § 46.

18 Marion 2008, 305.

19 Kant 1978, § 17.
} 
recurre a Husserl ${ }^{20}$ para establecer el principio de todos los principios, según el cual, «toda intuición donadora originaria es fuente de derecho para el conocimiento» ${ }^{21}$.

\subsection{LA EXPERIENCIA COMO FORMA LEGÍTIMA DE CONOCIMIENTO}

En los casos de conversión súbita se da la adquisición o impresión de un conocimiento, pero éste deriva directamente de la experiencia concreta, es decir, primero será el encuentro y, a raíz y motivado por éste, la certeza. Por consiguiente, la naturaleza del hecho será vivencial, acontecimiento «que se da». Pero, ¿a qué nos referimos exactamente cuando hablamos de experiencia y, más concretamente, de experiencia religiosa? Describe con exactitud Juan Martín Velasco sus características principales:

[...] su capacidad de poner en contacto con una realidad que se impone al sujeto como efectivamente existente; su condición de experiencia por contacto vivido con la realidad experienciada, sin pasar por el medio de los conceptos, ni del uso de los sentidos en relación con la realidad en cuestión, y, por tanto, superando el conocimiento objetivo: la conciencia de pasividad; la simplicidad; el carácter totalizador o englobante que se deriva de que el órgano de la experiencia no es ninguna facultad determinada sino el centro mismo del sujeto; la condición al mismo tiempo cierta y oscura; su carácter inefable; su repercusión sobre las capas afectivas del sujeto y su valor «fruitivo»; y su repercusión sobre la vida de las personas que ven en ellas un hito en su vida del que suelen guardar un recuerdo preciso y claramente situado en el tiempo y en el espacio 22 .

Pedimos disculpas por lo extenso de la cita, pero, en estas líneas, el fenomenólogo de la religión Martín Velasco hace una excelente síntesis de las características principales que suelen definir la experiencia religiosa. En este punto nos interesa destacar el hecho de que todo se origina en una experiencia particular y en un marco espacio-temporal delimitable. Este acontecimiento -porque «acontece»- supera el «conocimiento objetivo», pero no deja de ser «conocimiento»; podríamos decir que por contacto. La experiencia, por tanto, se revela y, en su revelarse, interpela, pues porta una verdad pertinente para la existencia del sujeto pasivo -veremos que la iniciativa corresponde al actante divino-. Por su parte, Lluís Duch, en su estudio La experiencia religiosa en el contexto de la cultura contemporánea ${ }^{23}$, asevera que la experiencia religiosa, al alcanzar la conciencia, «queda identificada» y aporta un sentido. Esto es, se adivina el donante y se extrae una enseñanza concreta pese a la posible oscuridad de este tipo de experiencias; es, por tanto, experiencia esclarecedora que de alguna forma resuelve el enigma del mundo.

\footnotetext{
20 Husserl 1993, § 24.

${ }^{21}$ Husserl 1993, § 24.

22 Martín Velasco 2006, 102.

23 Duch 1979, 40.
} 
Obviamente, la experiencia de Dios, aunque comparte ciertas estructuras con las experiencias ordinarias, tiene una naturaleza muy particular, diríamos que extraordinaria, pues se define por su total desemejanza respecto a la aprehensión del resto de objetos. Tanto percibir una mesa como percibir a Dios son experiencias, pero de características y consecuencias, a todas luces, diferentes. Para dilucidar la cuestión, debemos volver a Jean-Luc Marion y a lo que denomina como fenómeno saturado.

\subsection{PARTICULARIDADES DE LA EXPERIENCIA. FENÓMENO SATURADO}

Marion emplea esta denominación para referirse a una serie de fenómenos que escapan tanto a la fenomenología de Husserl como a los presupuestos metafísicos de Kant; y creemos que esta nueva especie de fenómeno se ajusta a los casos aquí presentados.

Los dos primeros condicionantes, o finitudes, que un fenómeno saturado tiene que sobrepasar son el yo y el horizonte. En primer lugar, para ser reducido a un yo que aprehende y, por tanto, codifica, se precisa que el fenómeno pueda reducirse «al estatuto de la objetividad finita» ${ }^{24}$, lo que va en detrimento de la propia donación del fenómeno, al que se le está exigiendo unas particularidades previas a su libre manifestación. En segundo lugar, ha de inscribirse dentro de una condición de posibilidad que llamamos horizonte, lo que, a su vez, exige un segundo grado de finitud previo a la intuición. Tanto uno como otro, en los casos de conversión súbita tratados, aparecen a posteriori, pero no como requisitos o condicionantes previos al fenómeno y a la intuición. El carácter súbito e insospechado propicia que, a la hora de la manifestación, el sujeto carezca de cualquier categoría para encauzar el fenómeno, que se muestra incausado e inaprehensible. Ahora bien, sí impone una nueva categoría significativa para el yo. Irrumpe e instaura, por sí mismo, una realidad. Es, por tanto, una intuición fundacional de sí misma, que no se pliega a la objetividad finita previa, sino que la abre a la infinitud, sin que ello vaya en detrimento de la certitud que insufla.

Se podría aducir, respecto al horizonte, que la manifestación divina queda enmarcada en el contexto religioso y cultural del sujeto paciente, en tanto que posibilidad. Y así es. En Manuel García Morente, por ejemplo, la teofanía es considerada automáticamente dentro de la tradición cristiana-católica. ¿Supone esto que el fenómeno deja de ser saturado por plegarse a un horizonte de posibilidades, en este caso, la tradición cultural y religiosa en que vive y piensa el protagonista? Depende del orden de factores. Puede pensarse que el sujeto ha tenido una experiencia de Dios y que la ha enmarcado en las categorías teológicas que conoce, lo que, efectivamente, supondría una reducción de la intuición a contenidos previos; o puede, por el contrario, que el fenómeno mismo se presente católico al margen de la cultura del sujeto paciente. Sea como fuere, tal y como apuntábamos más arriba, nuestra intención será descrip-

${ }^{24}$ Marion 2008, 324. 
tiva; nos interesará, pues, la intuición del sujeto paciente al margen de explicaciones culturales o psicologistas. Sin duda, dada la educación cultural de nuestros autores estudiados -intelectuales europeos del siglo pasado-, estaban hermenéuticamente preparados para la revelación, pero hasta su manifestación y resonancia -en terminología de Gaston Bachelard ${ }^{25}$ - no podemos hablar de contenido real.

Otro punto que trata Marion respecto al fenómeno saturado es su condición de «acontecimiento puro». Lo es en cuanto se impone a la percepción y no responde a la relación causa-efecto, al menos no de forma discernible. Asimismo, no se reduce a la analogía de las experiencias, por eso cobra una entidad especial, de acontecimiento:

Acontecimiento o fenómeno no previsible (a partir del pasado), no exhaustivamente comprensible (a partir del presente), no reproducible (a partir del futuro); en definitiva, absoluto, único $[\ldots]^{26}$

El fenómeno saturado vuelve a sobrepasar la metafísica kantiana, en tanto que supera el poder conocer del yo y aún así aparece. El desajuste entre los condicionantes de la experiencia y el fenómeno saturado provoca que no pueda constituir objeto ${ }^{27}$; pero esto no implica que la intuición sea vacía, sino que su contenido se impone de forma excepcional y «no-mentable» ${ }^{28}$. Si se resiste a las categorías no es por deficiencia, sino todo lo contrario: rebasa toda anticipación o condicionante, incluso teorización posterior, en su propia potencia. Se erige como verdad en su automanifestación. No es objeto porque no se deja mirar por el sujeto; más aún, es el otro actante, el divino, «el que se aparece», quien mira al sujeto paciente; para éste sería imposible devolver la mirada desde la ontología profana o terrenal. Se apunta en las Escrituras: «nadie puede ver a Dios y seguir viviendo» ${ }^{29}$.

Marion $^{30}$ habla de una contra-experiencia y lo relaciona con los actos fundados de Husserl, en donde la experiencia depende de eso que aparece y desborda para ser inteligible. El fenómeno saturado es inabarcable y se define por una sobreabundancia que impide la visión ordinaria; sin embargo, la intuición que genera es inequívoca y está sustentada por el propio acontecimiento. Se trata de una epifanía oscura, pero no vaga; inabarcable, pero no ininteligible.

\subsection{EL RECUERDO COMO ACTIVACIÓN DE LA EXPERIENCIA}

En este apartado, no podíamos dejar de comentar algo sobre el recuerdo. Insistamos en que los testimonios de que disponemos son reelaboraciones diferidas, por lo

\footnotetext{
${ }^{25}$ Cfr. Bachelard 1965, 8.

26 Marion 2008, 339.

27 Cfr. Marion 2008, 349.

${ }^{28}$ Marion 2008, 349.

29 Ex. 33,20.

${ }^{30}$ Cfr. Marion 2008, 351.
} 
que se torna fundamental conocer el rol que la rememoración adquiere en este procedimiento. Lo decíamos: no nos interesa, en última instancia, lo que al sujeto aconteció -hecho, por otra parte, inaccesible-, sino lo que relata que le sucedió. Podemos hacer algunas puntualizaciones, no obstante, que subrayen la importancia de la memoria en este aspecto, sin ir con ello en detrimento de la perspectiva fenomenológica que nos propusimos.

Si se quisiera hacer un estudio para la verificación o refutación de una experiencia de conversión -lo que no es nuestro cometido-, se debería incidir y mirar a contraluz la acción transformadora de la memoria, asumiendo de antemano, claro está, la intención de fidelidad del narrador para con lo que cree que vivió. «Quien recuerda reelabora», podría decirse para poner en duda la credibilidad de los testimonios de conversión. Sería factible, no obstante, verlo de dos maneras: a) el narrador-protagonista altera los acontecimientos, incluso inconscientemente, para extraer las consecuencias que le conviniesen; o b) el recuerdo va desbrozándose de lo accesorio para mejor conservar lo esencial. Lo señala el ya citado Chrétien ${ }^{31}$, el olvido es condición sine qua non de la memoria, pues un almacenaje total e indiscriminado impediría la conceptualización y, por tanto, vetaría cualquier género de conclusión. Recordemos al personaje Funes el memorioso, de Jorge Luis Borges, recogido en Ficciones: el protagonista, al no poder olvidar nada, se ve imposibilitado para comprender las categorías o la simple referencia semántica. Al no poder olvidar, no comprende la esencia, que permanece en su memoria con la misma vigencia que lo accidental. Así, el hecho de que la rememoración nunca pueda traer el fenómeno tal-como-fue, no debe guiarnos hacia el descrédito, pues se trata de un elemento constitutivo de la memoria. Concluye Chrétien: «Sin olvido, la historia deviene imposible» ${ }^{32}$.

Nos queda, no obstante, otra consideración respecto a la memoria y la teofanía. Se trata de lo que podría definirse como la cualidad de lo «inolvidable»:

[...] lo inolvidable no define la fuerza indeterminada de mi memoria en calidad de facultad -que conserva sin flanquear tal recuerdo de su elección, arbitrariamente-, sino lo propio de aquello que no se deja olvidar, de aquello que, de suyo, y como de antemano, alumbra con una claridad que nada puede apagar o encubrir ${ }^{33}$.

Aquí la posibilidad de «no olvidar» no corresponde a las capacidades del sujeto que rememora, sino que es condición del propio hecho que no se deja olvidar. Y, una vez más, vemos como en este fenómeno el acontecimiento se presenta como activo, mientras que el sujeto es cada vez más pasivo. Vemos un paso más en este cambio de roles donde el sujeto deviene objeto y viceversa.

\footnotetext{
31 Chrétien 2002, 61.

32 Chrétien 2002, 75.

33 Chrétien 2002, 97.
} 


\section{RASGOS FENOMENOLÓGICOS COMUNES}

\subsection{LA INTUICIÓN COMO REALIDAD DE LA EXPERIENCIA}

Según hemos considerado hasta ahora, la fuente de conocimiento en este caso no sería la razón, sino la intuición. Esto no indica que sea una aprehensión deficitaria o una adquisición de conocimientos de segundo orden, sino que constituye el método exigido por lo que se conoce. Lo revelado es de tal naturaleza que no es comprensible por la razón. Hablamos de adecuación de instrumento:

[...] el contemplativo se siente inmerso en un estado cognoscitivo que le permite aprehender directamente grandes verdades trascendentes. Pero estas verdades, paradójicamente, no están sujetas a la lógica ni al discurrir racional, que sobrepasan del todo $[\ldots]^{34}$

Podría aducirse que la intuición que genera la teofanía se vincula con el concepto de lo divino y que, por tanto, la intuición vendría respaldada por una categoría de la razón y se obraría la adaequatio. Sin embargo, ¿podemos afirmar que lo que consideramos como Dios pueda responder a un concepto de objeto? Difícilmente. Desde luego se trata de una categoría cultural-religiosa, un símbolo de pensamiento, pero nadie ha visto a Dios como para reconocerlo en adelante. Los fenómenos que aquí tratamos no responden a algo paranormal que luego el sujeto achaca a Dios como respuesta lógica; es decir, «como no puedo explicar esto, será cosa de ese ente inmaterial y omnipotente que conocemos como Dios». No. El núcleo fundamental de esta experiencia es el manifestarse de Dios, es más, se trata del único contenido articulable. No asistimos a una serie de indicadores que parezcan patentar la existencia de Dios debido a lo inexplicable de su contenido, sino al propio acto libre de la divinidad de darse a conocer en un momento y a una persona concreta. Nada le sucede al protagonista, salvo que se le ha incubado una certeza directamente. Si se le preguntara, «¿qué te ha pasado?», no te responderá diciendo «me ha pasado esto o aquello», sino con lo único que hará justicia a lo acaecido: Dios existe, yo me lo encontré ${ }^{35}$.

Asimismo, la intuición se nos presenta como el órgano predilecto de la fenomenología. Incluso sin un concepto, por así decirlo «claro», la intuición puede aportar contenidos sin necesidad de plegarse a los presupuestos o exigencias de la razón. Se expresa en esta línea Marion:

La intuición sin concepto resulta tan ciega como el concepto sin intuición resulta vacío; pero la ceguera es mejor que la vacuidad: incluso cegada, la intuición todavía da, mientras que el concepto, incluso si puede hacer ver lo dado, resulta en cuanto tal perfectamente vacío, bien incapaz pues de ver algo, sea lo que sea.

\footnotetext{
${ }^{34}$ López-Baralt 1996, 26.

35 Título del testimonio de conversión de André Frossard.
} 
La intuición sin concepto, aunque ciega, da todavía materia a un objeto; mientras que el concepto sin intuición, aunque no ciego, no ve nada, puesto que nada le ha sido dado a ver. En el reino del fenómeno, el concepto no es el rey, sino más bien la intuición que es la única que dispone del privilegio de dar $^{36}$.

Lo que aquí se produce es, en terminología de Lluís Duch ${ }^{37}$, una experiencia de apertura: una súbita iluminación de partes de la realidad que, hasta entonces, permanecían ocultas. Y decimos «iluminación», porque no se trata de los frutos de un proceso mental ni de los hallazgos de una serie de pesquisas filosóficas, sino de un descubrimiento repentino e infuso, pero fundamental y esclarecedor, que no podrá reducirse a contenidos conceptuales, aunque su repercusión vital será definitiva. Comenta san Máximo Confesor a propósito de estas experiencias:

[...] como el saber mismo en acto, que adviene más allá de todo concepto. Es también la participación en el objeto, que se revela más allá de todo pensamiento ${ }^{38}$.

Se produce una certeza tan inquebrantable, de tal seguridad, que el sujeto la distingue con prontitud del resto de experiencias, más sujetas al engaño, ya sea de los sentidos o de la razón. No se tratará, aunque cueste entenderlo -no podría ser de otra forma-, de una experiencia con un grado alto de certeza, sino la certeza misma en su manifestación; no es, así, susceptible de duda por parte del protagonista. Igualmente, la naturaleza de esa certeza propicia que el agraciado se la adjudique -más bien se la reconozca- a un más allá de nosotros mismos, una entidad, en este caso Dios, con una participación en la verdad mayor a la que acostumbramos, una entera participación, una participación fontal.

No obstante, el hombre ha de recurrir a lo que conoce para expresarse, de ahí que emplee los símiles de mayor seguridad de que dispone ${ }^{39}$. Recordemos los versos de san Juan de la Cruz:

a) Como atribución divina: «iQue bien sé yo la fonte que mana y corre,/ aunque es de noche! ${ }^{40}$

b) Símil natural para certidumbre sobrenatural: «Aquesta me guiaba/ más cierto que la luz del mediodía.» ${ }^{41}$

Aquí, la aparente contradicción entre «mediodía» y «de noche» se explica por las características de la experiencia. Hemos dicho que se trata de un fenómeno que no pasa por la razón, tampoco por los sentidos, que no se trata de un objeto ni es objetivable; sin embargo, al mismo tiempo se presenta como inconfundible para el sujeto, siendo el reconocimiento automático. Quizás no pueda ser de otra forma. La

36 Marion 2008, 319.

37 Duch 1979, 56.

38 Cit. en Duch 1979, 56.

39 Martín Velasco 1995, 63.

40 Juan de la Cruz 1969, 57.

41 Juan de la Cruz 1969, 29. 
percepción de la divinidad, parece que por necesidad, ha de producirse por canales diferentes de los que se utilizan para la percepción corriente; lo que no quita que el reconocimiento se produzca, a la vista del sujeto paciente, sin fallas, como si llenara una categoría que esperara ser colmada y que sólo ese ente podía colmar, como llave y cerradura; ahora bien, una categoría completamente ignorada hasta entonces. Comparábamos antes la percepción de una mesa y la percepción de Dios, pues bien, siendo ésta última de más dificultosa acotación, la certeza que genera es mayor que en el primer caso. En otras palabras, pese a que Dios ni se le sienta ni se le razone en ese caso, su presencia es más indubitable que la de la mesa sobre la que ahora escribimos.

Al mismo tiempo, hay que anotar que el conocimiento que concurre, y que hemos deslindado de un proceso mental al uso, tampoco tiene su base experiencial en los sentidos. Hay que recurrir, en este caso, a las apreciaciones relacionales de Martin Buber ${ }^{42}$. El filósofo austríaco-israelí denuncia que cualquier prescripción es inválida para abordar el fenómeno "protosimple del encuentro». No sirve aquí la apropiación u objetivación que el sujeto realiza al percibir el objeto, pues no se trata de una percepción de un ello, sino de un encuentro relacional. Dicha relación sólo puede tener lugar entre un Yo (sujeto paciente) y un Tú (interlocutor divino), de ahí que las categorías y prescripciones del objeto se quiebren o muestren obsoletas. Hablamos de un encuentro personal y no porque se obre una antropomorfización de la divinidad -cuyo ser no puede, por definición, ser circunscrito-, sino porque ese Ello divino pasa a ser Tú en cuanto toma la iniciativa de comunicarse con el hombre. En definitiva, no cabe percibir ni ver a Dios, únicamente cabe relacionarse con Él y siempre a modo de respuesta. Esto no supone que el Yo deba diluirse o desaparecer, lo que se debe superar es lo que Marion llama la «egología metafísica» ${ }^{43}$, así como de su síntesis e intención de objeto; elementos estos, como hemos ido viendo, imposibles para el tipo de experiencia que nos ocupa.

\subsection{GRACIA: LA INICIATIVA DE DIOS, SUJETO ACTIVO}

Entendemos por gracia la acción que corresponde a una iniciativa concreta de Dios a favor del hombre. La idea proviene del kairós griego que en mitología significaba el momento oportuno o propicio. Para la teología cristiana posterior, pasa a significar «el tiempo de Dios», es decir, «un tiempo de gracia divina» donde Dios interviene en la historia o se vive en especial consonancia con sus designios. En el contexto católico se emplea el término providencia, que denomina la intervención activa de la divinidad en la existencia del hombre, lo que confirma una trascendencia activa y participativa. Igualmente, según el misterio trinitario, estaríamos hablando del Espíritu Santo, intercesión de Dios en la historia entre Pentecostés y la futura Parusía. Carácter, pues, dinámico y religado:

\footnotetext{
${ }^{42}$ Cfr. Buber 2005.

${ }^{43}$ Marion 2008, 310.
} 
La gracia no es una mera cualidad. Es un momento dinámico. Ese momento dinámico puede ser interpretado como la presencia de Dios en las personas (gracia increada), y como esa especie de cualidad que esa presencia imprime en las personas (gracia creada) ${ }^{44}$.

Por otra parte, el proceso de conversión, según la ortodoxia católica, no puede obrarlo el hombre por sí mismo, sino que precisa de esa acción especial por parte de la divinidad que hemos denominado gracia, de ahí que hablemos de donatio, pues es recibida como regalo.

A la vez que el presentarse corresponde a la divinidad, que lo haga tiene una clara significación para el sujeto paciente. Siendo Dios la existencia y verdad suprema, desemejanza ontológica absoluta ${ }^{45}$ respecto al hombre, que se incline e inicie una comunicación personal con la criatura tiene consecuencias. En primer lugar, el Creador no se desvincula de su creación, sino que la atiende y se dirige a ella inaugurando un diálogo trascendente y confirmándose como interlocutor-elemento constitutivo de la tradición judaica-. La divinidad dejaría de ser un ente inalcanzable, inmutable en la cima ontológica, para ser un Dios Praessentissimus, ya que se da a conocer y reivindica su condición amorosa-relacional. Es, por tanto, Deus pro nobis.

Uno de los rasgos principales de esta gracia es la «gratuidad inmotivada» ${ }^{46}$. El sujeto no ha hecho ningún mérito para recibir la donación, más aún en el caso que nos ocupa, donde la conversión se obra súbitamente sin ningún tipo de ascesis. Esto incide en la consideración de regalo inmerecido. Podríamos hablar de arbitrariedad en la iniciativa divina, pero esto implicaría conocer los designios de Dios, realidad, si existiera, inaccesible para el hombre. Es elocuente al respecto el testimonio del ya citado André Frossard. Al comunicar su conversión a un amigo, éste le cuestiona: «¿Por qué a usted?» ${ }^{47}$ Frossard no tiene respuesta; quizás nadie.

Pese a que se ha podido entrever hasta ahora, veamos por qué nos hemos referido al sujeto como paciente. Partamos de Martín Velasco:

El hombre se comporta en las experiencias religiosas, en primer lugar, como sujeto pasivo. Toda experiencia religiosa es en definitiva «teopática». El hombre, más que aprender a Dios, más que conocerlo, lo recibe, lo padece $[\ldots]^{48}$

Tiene, por lo tanto, un carácter responsivo. Es Dios - siempre según la intuición del sujeto- quien toma la iniciativa y quien, en suma, actúa sobre el hombre. Éste únicamente puede aparejarse para recibir y aceptar la donación, pero, al fin y al cabo,

\footnotetext{
44 Zubiri 2007, 319.

45 Cfr. Martín Velasco 2006, 146.

46 Duch 1979, 56.

47 Frossard 1969, 144.

48 Martín Velasco 1995, 47.
} 
nada de la experiencia depende de él. Así, sería inexacto hablar de diálogo, ya que el sujeto paciente no puede responder a Dios en el marco de la interlocución. A lo sumo, puede virar su vida según lo percibido e intentar vivir en orden con el Dios manifestado. Hablamos con pleno derecho del sujeto paciente, porque no ve sino que es visto. Se comprueba en los testimonios: el hombre no ve a Dios, sino que siente la mirada de Aquél sobre él. Asimismo, el sujeto no puede gestionar la experiencia: no puede decidir cuándo empieza, cuándo acaba ni delimitar su contenido. Es un sujeto, si queremos decirlo de otra manera, espectador, testigo; lo que no quita que le afecte radicalmente.

Quien produce esta inversión es ese actante divino que toma la iniciativa y que, como hemos dicho, no es mirado, que implicaría la muerte del sujeto, sino que mira. Podríamos aplicarle los rasgos de lo que Marion llama icono:

Nombraremos este último tipo de fenómeno saturado «icono» porque ya no ofrece ningún espectáculo a la mirada, ni tolera la mirada de ningún espectador, sino que ejerce inversamente su propia mirada sobre el que lo encara. El que mira toma el lugar del que es mirado, el fenómeno manifestado se invierte en una manifestación no solamente en y de sí, sino estrictamente por y a partir de sí (automanifestación) -la paradoja invierte la polaridad de la manifestación tomando la iniciativa y no recibiéndola, dándola y no dándose ${ }^{49}$.

\subsection{CONTENIDO DE LA TEOFANÍA DESDE EL SUJETO PACIENTE}

Estamos hablando de una ruptura de nivel: el sujeto paciente es transportado desde la esfera cotidiana o profana al nivel de lo sacro, donde acontece la hierofanía. Lo superior, cuando irrumpe, trastorna la vida del hombre al tratarse de un nivel que le desborda y se confirma como completamente distinto al mundo en que suele manejarse. Pero, en puridad, qué dice percibir el sujeto. Lo hemos dicho: lo fundamental es la constatación de la existencia de Dios. Ahora bien, ¿qué matices toma? ¿Qué intuye el sujeto paciente?

En primer lugar, si Dios se manifiesta, ¿deja de ser incognoscible? ¿Acaso el sujeto paciente siente haber desentrañado la esencia de lo divino? Desde luego que no. La cualidad mistérica de la divinidad queda intocada. El sujeto constata la existencia de ese Misterio, pero sigue siendo, y ahora más que nunca, Mysterium tremendum. Cuando sólo era una posibilidad, que fuera incognoscible podía no ser más que un atributo racional-negativo del supuesto ente divino; sin embargo, ahora que se presenta, el Misterio se confirma como acuciante y por entero indiscernible. Y debe ser así: si Dios pudiera ser pensado, de alguna forma implicaría una subordinación a las categorías del pensamiento. Con la Presencia, deja de ser

\footnotetext{
49 Marion 2008, 374s.
} 
pensamiento para ser vida activa. Pasa de ser una Causa primigenia -lo que nos aleja del deísmo neutro- a personalizarse en un Tú que nos llama. Abandona definitivamente el ejercicio del pensamiento en virtud de su naturaleza mistérica para ser completamente realidad relacional y vivencial. Tan deslindado queda de las elucubraciones, que la experiencia de García Morente, por ejemplo, filósofo reputado, no distará de la que pudiera tener un analfabeto. El Misterio se impone y debe ser aceptado, no resuelto.

Otro atributo, que de alguna forma hemos apuntado, es la consideración de Summum Bonum:

Tampoco esta designación es para el sujeto religioso el resultado de la atribución a Dios de una propiedad que el hombre encuentre en su mundo y en sí mismo y que afirme de Dios en grado eminente aplicando el procedimiento de la analogía. Bien supremo es la manifestación que reviste el Misterio que el sujeto religioso reconoce cuando el rayo deslumbrador de su Presencia se difracta en esa faceta central de la persona que es su estimativa, su voluntad y su deseo ${ }^{50}$.

Incide Martín Velasco: cuando Dios se manifiesta al hombre, éste lo percibe como Bien supremo. No únicamente porque tome la iniciativa y «se rebaje» para tocar a su criatura, sino porque así lo intuye el sujeto paciente en el centro de su ser; dice Velasco: «su estimativa, su voluntad y su deseo». Difícilmente podríamos aquí definir con exactitud la palabra «amor», pero es ésta la característica principal que intuye el sujeto paciente. Siente la atención amorosa del que se manifiesta y cómo le embriaga. Apenas, decíamos, podemos realizar una definición satisfactoria del término. Entramos en el terreno de la afasia y lo inexpresable. Se trata de algo que sólo conoce quien lo experimenta, por eso vale emplear el verso de Lope de Vega para decir: «quien lo probó lo sabe» ${ }^{51}$.

En lo que respecta al sujeto paciente, topa con una experiencia radical, en tanto que se encuentra ante un salto ontológico absoluto, más allá de cualquier experiencia previa. El hombre se «sobrecoge» ${ }^{52}$ ante esa realidad que nada tiene que ver con las realidades que conoció con anterioridad porque se trata de la Realidad misma. Por lo tanto, su otredad es completa: no hay analogía posible, se trata de lo insospechado. Como era de esperar, se produce una fascinación y maravillamiento:

La atracción fascinadora que ejerce lo numinoso sobre el sujeto religioso contiene un primer aspecto que puede expresarse en términos de asombro y de admiración. El sujeto religioso queda literalmente «maravillado» por su aparición. Este asombro se distingue del que puede producir cualquier realidad mundana, y

\footnotetext{
50 Martín Velasco 2006, 151.

${ }^{51}$ L. Vega, parte del último verso del soneto Desmayarse, atreverse, estar furioso.

52 Martín Velasco 2006, 128.
} 
se distingue también cualitativamente del asombro y la admiración en los que los filósofos han visto el origen de la filosofía ${ }^{53}$.

Indagando en el «asombro», Marion afirma que esta pasión nos afecta cuando algo que sólo conocíamos parcialmente -idea de Dios para nuestro caso-, «se nos impone con una potencia tal que nos quedamos sumergidos por lo que se muestra, eventualmente hasta la fascinación» ${ }^{54}$. Podríamos hablar, siguiendo con Marion, de una de las cualidades del fenómeno saturado: insoportable según la cualidad. Cuando la intuición satura un fenómeno y sobrepasa cualquier anticipación conceptual, la mirada no puede soportar la magnitud y se produce un «deslumbramiento» ${ }^{55}$. Les sucedió a los prisioneros de la Caverna platónica cuando salieron al exterior e intentaron levantar la vista. No obstante, en el caso de la teofanía, el deslumbramiento no es un proceso doloroso ni angustioso para el hombre. Es cierto que «no puede soportar» lo que se le muestra debido al exceso del fenómeno, pero ese exceso se percibe como maravillamiento. No destruye al sujeto -aunque después matizaremos este punto-, sino que le da una dimensión e intensidad que no hubiera sospechado. Súbitamente se le clarifica el sentido de la existencia gracias a la irrupción de la divinidad, lo que supone una experiencia sin duda fortísima y radical, pero también gozosa en tanto que la Presencia se define, sobre todo, por el amor.

\subsection{EL HOMBRE NUEVO COMO IMAGEN PREDILECTA}

Sin duda, la imagen más elocuente y recurrida en los procesos de conversión es la del Hombre nuevo. La fuerza activa de la teofanía afecta al sujeto paciente hasta el punto de que tiene la impresión de haberse convertido en una nueva persona, literalmente. Incluso, como en el caso de san Pablo, llega a cambiarse el nombre, que pasa por ser lo más personal e identitario. Esto no quiere decir que el individuo cambie de personalidad o de físico de tal forma que no le reconozcan, sino que se obra una transformación interior tan radical, que ha de emplearse los términos muerte y nuevo nacimiento. Estudiosos como Mircea Eliade han encontrado esta estructura fundamental en los ritos iniciáticos de las religiones, por los que un miembro pasa a serlo plenamente tras un proceso de cambio y sintonización con la divinidad y su comunidad:

La mayor parte de las pruebas iniciáticas implican, de manera más o menos transparente, una muerte ritual a la que seguirá una resurrección o nuevo nacimiento. El momento central de toda iniciación viene representado por la ceremonia que simboliza la muerte del neófito y su vuelta al mundo de los vivos. Pero el que

\footnotetext{
${ }_{53}^{53}$ Martín Velasco 2006, 97.

${ }^{54}$ Marion 2008, 331.

55 Marion 2008, 334.
} 
vuelve a la vida es un hombre nuevo, asumiendo un modo de ser distinto. La muerte iniciática significa al mismo tiempo fin de la infancia, de la ignorancia y de la condición profana ${ }^{56}$.

Por lo tanto, la conversión servirá de renovatio, pero, para que se produzca una nueva criatura, la vieja ha de perecer, y es que «no puede echarse vino nuevo en odres viejosı ${ }^{57}$ :

La muerte iniciática se convierte en la condición sine qua non de toda regeneración espiritual [...] No hemos de perder de vista que la muerte iniciática significa a un tiempo el fin del hombre «natural», no cultural, y el paso a una nueva modalidad de vida: de un ser «nacido para el espíritu», esto es, que no vive tan sólo en una realidad «inmediata». La muerte iniciática se integra por tanto en el proceso místico mediante el cual el hombre se convierte en otro $^{58}$.

Se produce un nuevo nacimiento, imprescindible para albergar la nueva existencia, para convertirse en nova creatura en Cristo. Lo vimos al principio a propósito de Nicodemo: el hombre ha de volver a nacer en el Espíritu para vivir en gracia de Dios, para redimir su naturaleza adánica marcada con el sello de la muerte y el pecado. De la misma forma que Cristo sería el nuevo Adán que, con el árbol de la Cruz, redime la massa damnata adánica, el hombre ha de emular el procedimiento en pos de la resurrección. Así, será imprescindible una metanoia en la que el hombre transforme su existencia o, más bien, deje que Dios la transforme.

En el ámbito católico, existe un sacramento que obra expresamente este proceso: el bautismo. A través del agua -signo de vida y muerte, así como de tránsito-, se produce el ingreso del neófito en la Comunidad de los fieles. En las conversiones, hemos creído ver ciertas concomitancias con las lágrimas del converso. Siempre que concluye el proceso, el agraciado rompe a llorar. Bien podemos entender la circunstancia como un reflejo fisiológico-emocional ante el acontecimiento; pero, al mismo tiempo y sin ir en detrimento de lo anterior, ver en las lágrimas un avance de las aguas bautismales que producen la muerte del hombre viejo para dejar vía libre al nuevo alumbramiento. Por lo tanto, las lágrimas pueden entenderse como depuración del hombre antiguo. Dice san Cipriano a propósito del agua bautismal y la conversión en una carta remitida a Donato:

Pero cuando la suciedad de mi vida anterior fue lavada por medio del agua regeneradora, una luz de arriba se derramó en mi pecho ya limpio y puro. Después que hube bebido del Espíritu celeste, me encontré rejuvenecido con un segundo nacimiento y hecho un hombre nuevo: de manera milagrosa desaparecieron de re-

\footnotetext{
56 Eliade 1958, 12.

57 Mc. 2, 22.

58 Eliade 1958, 216.
} 
pente las dudas, se abrió la cerrazón, se iluminaron las tinieblas, se hizo posible lo que antes parecía imposible ${ }^{59}$.

Podemos, por último, traer a colación de nuevo la cita bíblica que afirma «que nadie puede ver a Dios y seguir viviendo» ${ }^{60}$. En las teofanías que tratamos no se produce un avistamiento completo de la divinidad, pero sí la constatación de su existencia y condición filial. Esto, amén de la metanoia aquí analizada, requiere que el hombre muera para dicha contemplación, ya que el salto ontológico no puede hacerlo desde su naturaleza menor; deberá despojarse para soportar la Presencia ${ }^{61}$. Así, la muerte como condición sine qua non para constatar lo que a los vivos les está vedado. Morirá primero y nacerá después, y todo como consecuencia de las condiciones de la experiencia que sufre. Dibuja el literato Paul Claudel, converso en París:

L'état d'un homme qu'on arracherait d'un seul coup de sa peau pour le planter dans un corps étranger au milieu d'un monde inconnu est la seule comparaison que je puisse trouver pour exprimer cet état de désarroi complet ${ }^{62}$.

\subsection{CONSECUENCIAS VITALES DE LA TEOFANÍA}

Hemos ido dando una perspectiva católica a nuestro análisis porque así es percibido por los protagonistas. El fenómeno no se produce, cabe decir, en el vacío; no se trata de una experiencia vaga que el sujeto no pueda escrutar, sino todo lo contrario. Pese a su inefabilidad, el encuentro tiene una significación muy concreta para el hombre y repercute decisivamente en su vida. Descubre una verdad y ésta le transforma. Lo pone de relevancia María Zambrano en su comentario al género de la confesión:

La evidencia suele ser pobre, terriblemente pobre en contenido intelectual. Y, sin embargo, opera en la vida una transformación sin igual que otros pensamientos más ricos y complicados no fueron capaces de hacer ${ }^{63}$.

Según Buber ${ }^{64}$, la actuación de la Presencia genera tres realidades distintas pero inseparables:

\footnotetext{
59 Cipriano 1964, Ad. Donatum, 3.

60 Éx. 33, 20.

61 Para una interpretación psicologista de este fenómeno, vid. James 2002, conferencia VIII.

62 Claudel 1965, 1011. Ofrecemos para Ma conversion una traducción propia sobre el texto original propuesto: «El estado de un hombre al que de una vez se le arrancara la piel para trasplantarlo a un cuerpo extraño, en un mundo para él desconocido, es la única comparación que puedo encontrar para ilustrar ese estado de total desconcierto.»

63 Zambrano 1995, 69.

64 Cfr. Buber 2005, 95.
} 
a) Compenetración con quien se manifiesta.

El Hombre nuevo, a partir de ahora, sólo puede vivir plena y libremente si, paradójicamente, lo hace en unión con el Otro. Se crea, por así decirlo, una dependencia absoluta que convertirá la existencia del sujeto en un camino cristocéntrico. Es en esa relación donde encuentra una plenitud antes insospechada.

Así, el hombre, que es animal relacional, no encuentra completitud hasta que establece la relación con el ente relacional por excelencia. Mientras que en su contacto con lo demás siempre puede estar sujeto a cierta reificación, con la divinidad es imposible, ya que ésta no puede relegar su ser personal ni puede ser ninguneada por el sujeto una vez manifestada. Por lo tanto, la relación con Dios es relación absoluta de la que el hombre ya no se desliga. No se trata de que el hombre se disuelva para unirse al completamente Otro, sino que su propio ser personal ya no puede-quiere vivir separado de su fuente.

b) Confirmación de sentido.

Esta Presencia, como decíamos, orienta la vida del testigo bajo un nuevo fin: cumplir la voluntad de Dios. La existencia, por tanto, cobra un sentido concreto. Esto dota a la persona de lo que Lluís Duch ha llamado «pensamiento sacramental»" según el cual se percibe «al mismo tiempo lo divino y lo humano, lo trascendente y lo inmanente, lo eterno y lo temporal» ${ }^{66}$. Todo lo existente es ahora iluminado bajo una nueva luz, bajo ese nuevo cometido que lo abarca todo. Esto no supone que se renuncie al mundo ni se devalúe en comparación con la divinidad manifestada, sino que ésta lo embarga todo, todo lo existente, incluido, es obvio, el mundo físico. Todo queda circunscrito bajo la teleología divina, por lo que se difumina la frontera entre lo sagrado y lo profano, siendo todo obra de Dios y entrando en su proceso relacionaltrascendente. Encontramos una nueva visión de la realidad sub specie divinitatis, donde todo tiene significación divina.

Apartar la vista del mundo no es dirigirse a Dios; empecinarse en el mundo tampoco es acercarse a Dios; pero quien ve el mundo en Él está en su presencia. Decir «aquí el mundo, allí Dios», eso es lenguaje-Ello; y decir «Dios en el mundo», eso es otro lenguaje-Ello. Pero no excluir nada, no preterir nada, incluirlo todo, el mundo entero, en el Tú, conceder al mundo su derecho y su verdad, no captar nada junto a Dios sino todo en Él, he aquí la plena relación ${ }^{67}$.

La vida se ve ahora bajo un nuevo foco. Y no sólo el presente y el futuro, sino también el pasado. En todos los conversos vemos una revisión de todo lo pretérito como itinerario hacia Dios. Sobre todo en nuestros casos de naturaleza súbita, no es tan fácil establecer el recorrido previo, ya que la irrupción de la gracia se produce de

\footnotetext{
65 Duch 1979, 46.

66 Duch 1979, 46.

67 Buber 2005, 72.
} 
forma insospechada; sin embargo, en todos ellos vemos un repaso de su vida pasada en torno a la epifanía. En todos los escritos, con más o menos extensión, se vuelve la vista al pasado y se contemplan los hechos biográficos según el encuentro, esto es, viendo lo que le predisponía o no para acoger a Dios. Por lo tanto, la teofanía se establece como centro gravitatorio, vivencial, filosófica y narrativamente. No en vano, el sujeto paciente descubre su «destino», por lo que no resulta sorprendente que eche la vista atrás para ver los pasos que le han conducido hasta él.

Una última consecuencia de este recién adquirido sentido es la conciencia de pecado. En primer lugar, porque se cumple el requisito previo: nadie que ignore a Dios peca, en el sentido de que la falta es respecto a Dios, así que quien lo ignorara, no es susceptible de pecado, al menos de su apreciación. Ahora bien, en el caso de encuentro con la divinidad, esta conciencia despierta y el hombre, en comparación con la beatitud y excelsitud de lo que se le revela, se considera indigno. Por lo tanto, podríamos decir que el pecado del hombre se evidencia en contraste con la santidad divina, ante su superejemplaridad en terminología de Javier Gomá Lanzón ${ }^{68}$. La conciencia de pecado emana como corolario del conocimiento de Dios: sólo quien conoce su voluntad es capaz de distinguir la transgresión.

No obstante, esta toma de conciencia no abruma al sujeto porque, al mismo tiempo, entra en contacto con el atributo de la misericordia. La revelación no es percibida como imposición, aunque sí como compromiso, pues su mensaje es puramente salvífico, de ahí que produzca una alegría que los narradores procuran comparar y describir, pese a que fracasen en su intento de traslación y comunicación por la inefabilidad del contenido.

c) Plasmación del sentido en la vida presente.

Por último, la epifanía acaba repercutiendo definitivamente en la vida del hombre; más aún, es la última certificación de su origen. Transforma su vida para sintonizarla con lo que Dios quiere, que, al mismo tiempo, es el único camino para su «realización perfecta». El hombre ya no vive para sí, sino para Dios, y hace suya la exhortación evangélica a perder la vida para ganarla ${ }^{69}$. En adelante, veremos un comportamiento de acendrada religiosidad en el sujeto y lo hará impelido y respaldado por el descubrimiento de la epifanía. A partir de entonces, cualquier lejanía respecto a Dios equivale a ir en detrimento de su propia plenitud.

Finalmente, el contenido de la revelación también adquiere consecuencias vitales y sociales concretas y, en un contexto cristiano, esto implica trabajar para el prójimo, para el hermano - filiación colegida desde el Padre-. Se abre entonces un periodo de progresiva imitación de Cristo, finalidad última del cristiano.

Como hemos anotado ya, aunque el descubrimiento sea experiencial y subjetivo, tiene consecuencias universales, por lo que no ha de extrañar que el sujeto sienta cierto imperativo de prédica, cuanto menos de difusión. Los propios escritos de con-

\footnotetext{
${ }^{68}$ Cfr. Gomá Lanzón 2013.

${ }^{69}$ Cfr. Lc. 9, 24.
} 
versión son métodos para ello. Se lee en Hch 4, 20: «No podemos callar lo que hemos visto y oído».

\section{CONCLUSIONES}

A lo largo de estas páginas hemos constatado las características comunes que emparentan los casos de conversión súbita, desde la perspectiva fenomenológica y siempre partiendo de los textos autógrafos de sus protagonistas. Se ha podido apreciar que, en el marco de la conversión súbita, se produce una certeza instantánea que se aprehende por medio de la intuición y que nos fuerza a hablar de acontecimiento puro según los presupuestos fenomenológicos. Esto, a su vez, genera un haz de imágenes y consecuencias, como será la muerte iniciática y la imagen del Hombre nuevo, así como la afasia en el campo narrativo.

Hemos pretendido así una investigación a través de las huellas. Allí donde está nuestro objeto de estudio -Dios-, no podemos acceder nosotros, por lo que se ha procurado el máximo acercamiento a través de la experiencia de quienes fueron abrasados por la irrupción del misterio. Sería como estudiar las características de un huracán a través del paisaje desolado que deja a su paso. Nos hemos centrado, por así decirlo, en experiencias místicas de individuos no místicos, de forma que permanezca intocada la frescura de la experiencia, y la designación mística, en su bisoñez, resalte los paralelismos del acontecimiento. La estupefacción del testigo y la puntualidad de la experiencia nos brindan la virginidad idónea para una comparación que se ha demostrado factible, prácticamente palpable.

\section{BIBLIOGRAFÍA}

Agustín de Hipona, Obras de San Agustín, (trad.lati.), Madrid,1969.

Agustín de Hipona, Las confesiones, (trad.lati.), Madrid, 2003.

G. Bachelard, La poética del espacio, (trad.fran.), Méjico, 1965.

M. Buber, Yo y Tú, (trad.ingl.), Madrid, 2005.

Cipriano, Obras de San Cipriano: Tratados. Cartas, (trad.lati.), Madrid, 1964.

P. Claudel, Oeuvres complètes, Paris, 1965.

J-L. Chrétien, Lo inolvidable y lo inesperado, (trad.fran.), Salamanca, 2002.

J-L. Chrétien, La joie spacieuse, Paris, 2007.

L. Duch, La experiencia religiosa en el contexto de la cultura contemporánea, Barcelona, 1979.

M. Eliade, Iniciaciones misticas, (trad.ingl.), Madrid, 1958.

A. Frossard, Dieu existe, je L'ai recontré, Paris, 1969.

M. García Morente, El «Hecho Extraordinario», Madrid, 2002.

O. Gónzalez de Cardedal, Cuatro poetas desde la otra ladera, Madrid, 1996. 
E. Husserl, Ideas relativas a una fenomenología pura y una filosofía fenomenológica, (trad. alem.), Méjico, 1993.

M. Jacob, Art chrétien, récit de ma conversion, Paris, 1964.

W. James, Las variedades de la experiencia religiosa: estudio de la naturaleza humana, (trad. ingl.), Barcelona, 2002.

Juan de la Cruz, Obras escogidas, Madrid, 1969.

H. Jürgen Baden, Literatura y conversión, (trad.alem), Madrid, 1969.

I. Kant, Crítica a la razón pura, (trad.alem.), Madrid, 1978.

S.J. Lelotte, Convertidos del siglo XX, (trad.fran.), Madrid, 1956.

J-L. Marion, Siendo dado, (trad.fran.), Madrid, 2008.

J. Martín Velasco, Introducción a la fenomenología de la religión, Madrid, 2006

J. Martín Velasco, La experiencia cristiana de Dios, Valladolid, 1995.

J. Martín Velasco, El hombre y la religión, Madrid, 2002.

J. Oroz, San Agustín. Cultura clásica y cristianismo, Salamanca, 1988.

V.V.A.A. (ed. L. López-Baralt), El sol a medianoche, Valladolid, 1996.

L. Wittgenstein, Investigaciones filosóficas, (trad.alem.), Barcelona, 2004.

M. Zambrano, La confesión: género literario, Madrid, 1995.

X. Zubiri, El hombre y Dios, Madrid, 2007. 